\title{
Hyaline Cell-Rich Apocrine Mixed Tumor with Cytologic Atypia
}

\author{
Chika Ohata
}

Department of Dermatology, Kurume University School of Medicine, Kurume, Japan

\section{Keywords}

Hyaline cell-rich apocrine mixed tumor · Cytologic atypia $\cdot$ Chondroid syringoma - Monster cell

\begin{abstract}
Hyaline cell-rich apocrine mixed tumor is relatively rare, and it often possesses atypical cells. Despite the presence of atypical cells, other histopathological features such as well circumscription, smooth border, predominance of bland cells, and no mitotic figures lead to classify these tumors as benign. In addition, no recurrence or metastasis has been reported even when cytologic atypia is identified. Here we report a case of hyaline cell-rich apocrine mixed tumor with cytologic atypia, which did not recur for 14 months after excision.
\end{abstract}

(c) 2018 The Author(s)

Published by S. Karger AG, Basel

\section{Introduction}

Following the report of the presence of hyaline cells in a pleomorphic adenoma, a salivary gland counterpart of apocrine mixed tumor (chondroid syringoma) [1], the presence of hyaline cells in apocrine mixed tumor also started to be noticed [2]. Although a previous study revealed that $40 \%$ of apocrine mixed tumor contained hyaline cells, the amount varied from few to many [3]. Despite being a relatively common cell type, the hyaline cell-rich variant is rare. Approximately 30 cases of hyaline cell-rich apocrine mixed tumor, also known as hyaline cell-rich chondroid syringoma, have been reported to date [2, 4-10]. A previous study reported that 17 out of 18 apocrine mixed tumors with cytologic atypia were a hyaline cellrich variant [8]. In this report, we present another case of hyaline cell-rich apocrine mixed tumor with cytologic atypia. 
Fig. 1. The patient presented with a skin-colored nodule $6 \times 6 \mathrm{~mm}$ in size on the left lower eyelid.
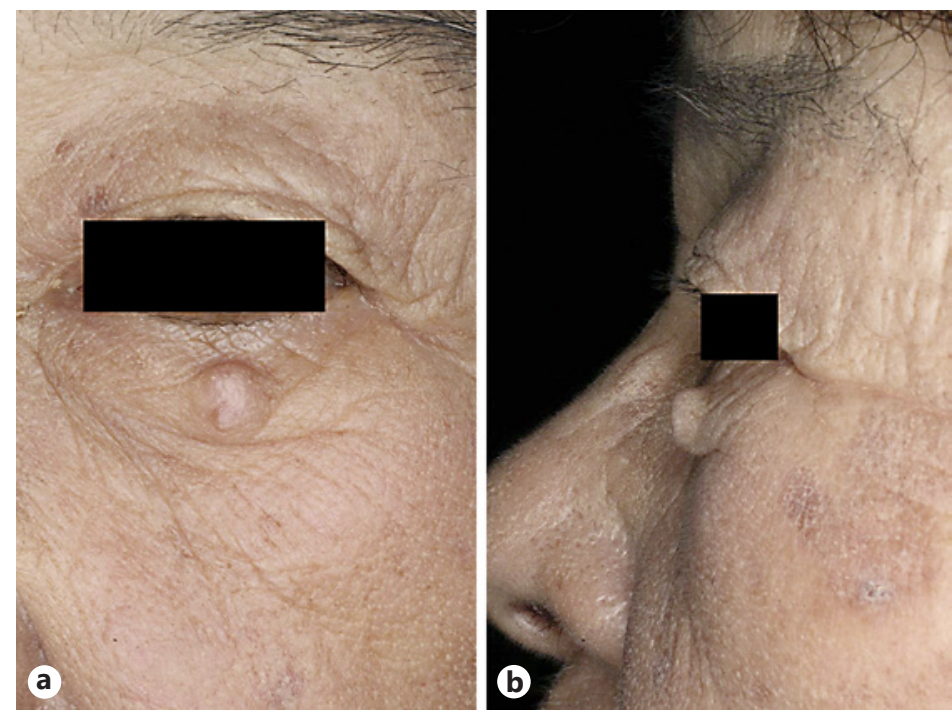

\section{Case Report}

An 80-year-old woman presented with a 2-year history of a nodule on the face. Physical examination revealed a skin-colored nodule of $6 \times 6 \mathrm{~mm}$ in size on the left lower eyelid (Fig. 1 ). Histopathological examination of the totally excised lesion revealed a well-circumscribed nodular lesion with a smooth border in the dermis and subcutis (Fig. 2a). The lesion consisted of an epithelial component and a myxoid stroma (Fig. 2b). The epithelial components were arranged in large and small aggregations with or without tubular structures, which occasionally showed apocrine secretion (Fig. 2b). Within the myxoid stroma, single epithelial cells were observed (Fig. 2b). Most epithelial cells were plasmacytoid hyaline cells with homogeneous, deeply eosinophilic cytoplasm, and signet-ring type cells were occasionally seen (Fig. 2c). Some plasmacytoid hyaline cells had abundant eosinophilic cytoplasm and large oval to polygonal nuclei with indistinct nucleoli, and a few extremely large atypical cells presented large bizarre nuclei with small nucleoli; the latter can be called monster cells (Fig. 2d). No mitotic figures were found. Hyaline cells were positive for S-100 protein, AE1/ AE3, CAM 5.2, and vimentin (Fig. 3) but negative for epithelial membrane antigen, p63, smooth muscle actin, desmin, cytokeratin 7, and carcinoembryonic antigen. Atypical cells were negative for Ki-67 and p53. The lesion has not recurred during the 14 months after the excision.

\section{Discussion}

Hyaline cell-rich apocrine mixed tumor affects patients between their twenties and seventies with prominent male predilection [2, 4-10]. Earlier cases were located in extremities $[2,4,5]$, whereas the recent cases also involved the face and neck $[6,8,9]$, in addition to extremities [7-10]. The sizes of the tumor were approximately up to $25 \mathrm{~mm} \mathrm{[2,4-10].}$

Although most of the earlier cases of hyaline cell-rich apocrine mixed tumor did not show cytologic atypia $[2,5-7,10]$, the relatively recent cases contained atypical cells $[4,8]$. In the study of 18 cases of apocrine mixed tumors with cytologic atypia by Kazakov et al. [8], 17 cases were hyaline cell-rich variant. All 18 cases were judged as benign because the majority 

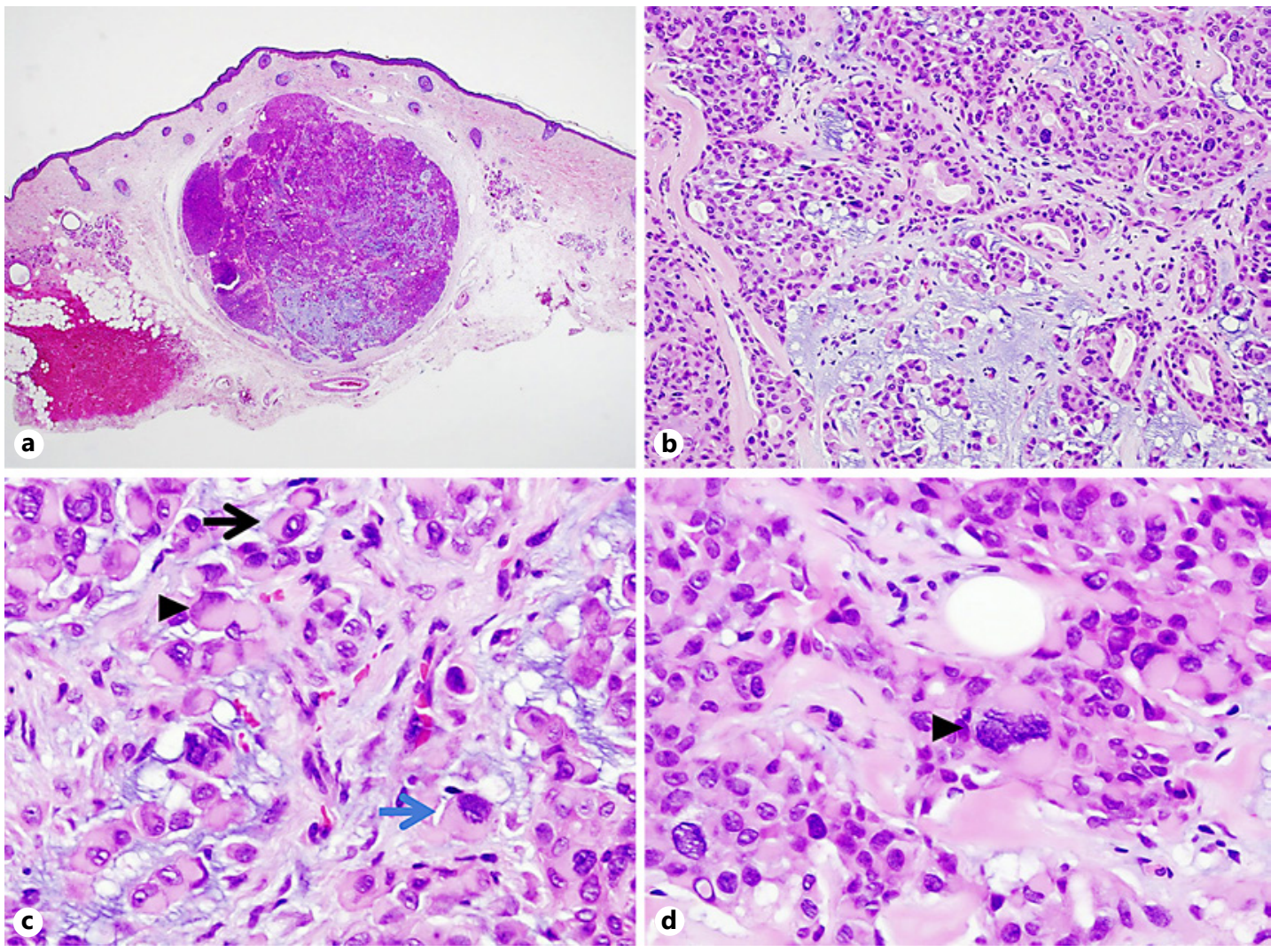

Fig. 2. a Histopathological examination revealed a well-circumscribed nodular lesion in the dermis and subcutis. HE. $\times 2$. $\mathbf{b}$ The lesion consisted of an epithelial component and a myxoid stroma. The epithelial components were arranged in large and small aggregations with or without tubular structures. Within the myxoid stroma, single epithelial cells were observed. HE. $\times 20$. c The predominant cell type was plasmacytoid hyaline cells (black arrow), but signet-ring type cells were also seen (arrow head). There were some large atypical cells (blue arrow). HE. $\times 40 . \mathbf{d}$ A monster cell (arrow head), an extremely large atypical cell, was also observed. HE. $\times 40$.

of the lesions manifested a vertical orientation, good circumscription, and smooth or only focally irregular borders [8]. Similarly, we diagnosed the present case as a benign tumor based on the well circumscription, smooth border, predominance of bland cells, and no mitotic figures, despite the presence of extremely large atypical cells. No recurrence or metastasis was reported in patients with hyaline cell-rich apocrine mixed tumor with cytologic atypia. Cytologic atypia can lead to the wrong diagnosis of a malignant tumor; therefore, to be aware of this change is important.

Electron microscopic studies revealed that hyaline in hyaline cells correlates with densely aggregated intermediate filaments [2, 3]. In addition, a previous report confirmed myoepithelial differentiation of hyaline cells based on the coexpression of cytokeratins and S-100 protein [8]. The immunohistochemical results of the present case also support the myoepithelial nature of hyaline cells. Some previous studies emphasized the absence of definitive myoepithelial features such as smooth muscle actin in hyaline cells and proposed an epithelial origin [3, 6]. However, Kazakov et al. [8] denied epithelial origin. In their study, hyaline cells ultrastructurally showed intermediate filaments, including tonofilaments, and thin filaments with densities and pinocytic vesicles, which indicated myoepithelial differentiation. Kazakov et al. [8] also emphasized that hyaline cells, whether in salivary glands or skin, may represent 

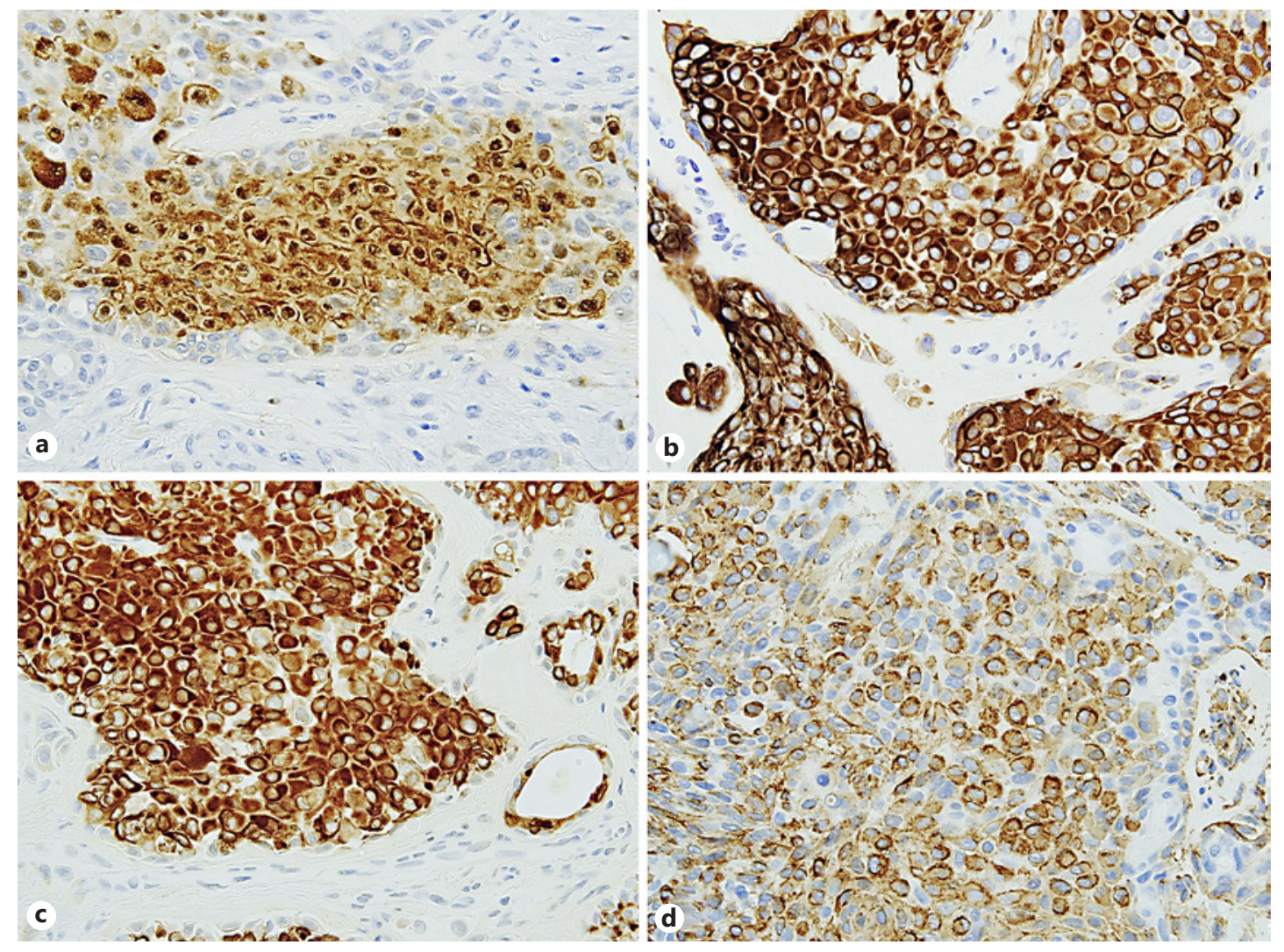

(c) 2018 The Author(s). Published by S. Karger AG, Basel www.karger.com/dpa

Fig. 3. Hyaline cells were positive for S-100 protein (a), AE1/AE3 (b), CAM 5.2 (c), and vimentin (d). $\times 40$.

just a modified myoepithelial cell, which under specific conditions can produce morphologically recognizable actin microfilaments.

In 1989, Argenyi et al. [3] reported that hyaline cells were relatively common in apocrine mixed tumor, and that they frequently showed signs of degeneration, ranging from ballooning to fragmentation. Kazakov et al. [9] reported 4 cutaneous apocrine mixed tumors with intravascular tumor deposits. In all cases, there were either blood or lymphatic vessels containing small intraluminal neoplastic cells, which had the appearance of hyaline cells. If hyaline cells correspond to degenerated constituent cells, intravascular hyaline cells could correspond to degenerated cells being eliminated rather than a metastasis feature.

Kazakov et al. [9] classified hyaline cell-rich apocrine mixed tumor with intravascular tumor deposits as a benign tumor because this variant did not have cytologic atypia. The present case did not have intravascular tumor deposits. No hyaline cell-rich apocrine mixed tumor has been reported presenting both cytologic atypia and intravascular tumor deposits. However, concurrent occurrence might be possible, and it would be difficult to exclude malignancy in that case. However, malignant apocrine mixed tumor is very rare, and no malignant hyaline cell-rich variant has ever been reported.

Besides malignant apocrine mixed tumor, differential diagnosis includes tumors possessing hyaline cells, such as rhabdoid melanoma, extraskeletal myxoid chondrosarcoma, parachordoma, and cutaneous myoepithelioma [7]. Rhabdoid melanoma expresses melan A and HMB45 [11,12], and extraskeletal myxoid chondrosarcoma is positive for neuron-specific enolase and synaptophysin [13]. Parachordomas consist of epithelioid cells and phys- 
aliphorous cells (cells with vacuolated cytoplasms) [14]. Cutaneous myoepithelioma never shows ductal or syringomatous epithelial structures or cartilaginous areas [15].

In conclusion, the present case was a hyaline cell-rich apocrine mixed tumor with cytologic atypia. The atypia may be due to degeneration rather than malignant transformation. No case with hyaline cell-rich apocrine mixed tumor with cytologic atypia was reported to recur or metastasize, and this suggests the benign nature of this disease.

\section{Statement of Ethics}

The manuscript was prepared in compliance with all ethical and confidentiality guidelines and principles.

\section{Disclosure Statement}

The author has no conflicts of interest to disclose.

\section{References}

1 Lomax-Smith JD, Azzopardi JG: The hyaline cell: a distinctive feature of "mixed" salivary tumours. Histopathology 1978;2:77-92.

2 Mambo NC: Hyaline cells in a benign chondroid syringoma. Report of a case and findings by conventional and electron microscopy. Am J Dermatopathol 1984;6:265-272.

3 Argenyi ZB, Goeken JA, Balogh K: Hyaline cells in chondroid syringomas. A light-microscopic, immunohistochemical, and ultrastructural study. Am J Dermatopathol 1989;11:403-412.

4 Banerjee SS, Harris M, Eyden BP, et al: Chondroid syringoma with hyaline cell change. Histopathology 1993; 22:235-245.

5 Ferreiro JA, Nascimento AG: Hyaline-cell rich chondroid syringoma. A tumor mimicking malignancy. Am J Surg Pathol 1995;19:912-917.

6 Nakayama H, Kishi A, Kajihara H: Hyaline cell-rich chondroid syringoma: epithelial nature of the hyaline cells. Jpn J Clin Oncol 1996;26:237-242.

7 Reis-Filho JS, Silva P, Milanezi F, et al: Hyaline cell-rich chondroid syringoma: case report and review of the literature. Pathol Res Pract 2002;198:755-764.

8 Kazakov DV, Bisceglia M, Spagnolo DV, et al: Apocrine mixed tumors of the skin with architectural and/or cytologic atypia: a retrospective clinicopathologic study of 18 cases. Am J Surg Pathol 2007;31:1094-1102.

9 Kazakov DV, Kacerovska D, Skalova A, et al: Cutaneous apocrine mixed tumor with intravascular tumor deposits: a diagnostic pitfall. Am J Dermatopathol 2011;33:775-779.

10 Ramaswamy AS, Yenni VV, Wilfred C, et al: Hyaline cell-rich chondroid syringoma of the finger. Indian J Dermatol 2011;56:217-219.

11 Abbott JJ, Amirkhan RH, Hoang MP: Malignant melanoma with a rhabdoid phenotype: histologic, immunohistochemical, and ultrastructural study of a case and review of the literature. Arch Pathol Lab Med 2004;128: 686-688.

12 Chung BY, Ahn IS, Cho SI, et al: Primary malignant rhabdoid melanoma. Ann Dermatol 2011;23:S155-S159.

13 Boyd AS: Chromosomal translocation-negative cellular extraskeletal myxoid chondrosarcoma in an adolescent female. J Cutan Pathol 2012;39:872-876.

14 Imlay SP, Argenyi ZB, Stone MS, et al: Cutaneous parachordoma. A light microscopic and immunohistochemical report of two cases and review of the literature. J Cutan Pathol 1998;25:279-284.

15 Michal M, Miettinen M: Myoepitheliomas of the skin and soft tissues. Report of 12 cases. Virchows Arch 1999; 434:393-400. 